LETTER TO JMG

\title{
Linkage of ulcerative colitis to the pericentromeric region of chromosome 16 in Italian inflammatory bowel disease families is independent of the presence of common CARD15 mutations
}

\author{
V Annese, A Latiano, O Palmieri, H-H Li, P Forabosco, A Ferraris, A Andriulli, M Vecchi, \\ S Ardizzone, M Cottone, B Dallapiccola, E Rappaport, P Fortina, M Devoto
}

J Med Genet 2003;40:837-841

C rohn's disease (CD) and ulcerative colitis (UC) are the two main clinical subtypes of inflammatory bowel disease (IBD), a common complex disease with a frequency in Western populations of about 1 in $1000 .{ }^{1} \mathrm{~A}$ strong genetic susceptibility to IBD is supported by several epidemiological studies, ${ }^{2}$ and the existence of both specific and common susceptibility genes for CD and UC has been postulated. ${ }^{3}$

Several candidate loci for IBD have been identified following whole genome scans in different populations (reviewed in Bonen \& $\mathrm{Cho}^{4}$ ). Among these, a locus in the pericentromeric region of chromosome 16 denoted $I B D 1^{5}$ was found consistently in linkage to $\mathrm{CD}$ in several independent studies $^{4}$ and in a large collaborative study by the IBD International Genetics Consortium. ${ }^{6}$ Most of these studies, with few exceptions, ${ }^{7}$ reported negative or non-significant linkage of the same locus to UC. Allelic variants of single nucleotide polymorphisms (SNPs) in the CARD15 gene, located in the $I B D I$ region, have since been demonstrated to confer susceptibility to $\mathrm{CD}$, but not to UC in several populations $^{8-10}$ (also reviewed in Bonen \& $\mathrm{Cho}^{4}$ ).

In a previous study, we reported positive non-parametric linkage (NPL) scores in the IBDI region in both our CD and UC families, ${ }^{11}$ with the highest scores occurring at markers D16S419 and D16S514, respectively. Marker D16S419 is located approximately $5 \mathrm{cM}$ away from CARD15, while Dl6S514 is located almost $20 \mathrm{cM}$ away on chromosome 16q. To follow up on these results, we typed 10 additional microsatellite markers in the chromosome 16 region of positive linkage in a total of 90 Italian IBD families, and repeated the linkage analysis after excluding 26 families with previously reported CARD15 SNP susceptibility alleles. The observation of a broad region of positive NPL scores in our UC families suggests that genes conferring susceptibility to this form of IBD may be located in the pericentromeric region of chromosome 16.

\section{MATERIALS AND METHODS}

Patients and families

Our linkage analysis cohort consists of 90 Italian families with two or more members affected by IBD recruited through a multicentre program of the IG-IBD (Italian Group for Inflammatory Bowel Disease) involving 12 centres throughout Italy. The cohort comprises 41 of 58 families included in our previous analysis of the IBDI region ${ }^{11}$ for which DNA samples were still available, and 49 new families that had never before been analysed. A total of 108 Italian unrelated healthy controls were also recruited from the same regions of origin of the patients. The local ethics committees of the

\section{Key points}

- Allelic variants of single nucleotide polymorphisms of the CARDI 5 gene, located on chromosome 16q, are known to cause susceptibility to Crohn's disease (CD), but not ulcerative colitis (UC). Previous studies suggested that linkage to the IBDI region on chromosome $16 q$ was present in both CD and UC families in the Italian population.

- In this study, we tested a group of Italian inflammatory bowel disease families for the three most common CARDI5 single nucleotide polymorphisms known to affect risk of CD (R702W, G908R and L1007fsinsC).

- We show that NPL scores in the IBDI region remain positive in those families that tested negative for the presence of the CARD 15 susceptibility alleles, including families of patients with UC.

- Our results suggest that additional genes in the pericentromeric region of chromosome 16 may affect risk of inflammatory bowel disease.

collaborating institutions approved this study, and informed consent was obtained from each participant.

Patients were classified as having CD or UC on the basis of clinical, endoscopic, radiological, and pathological data. ${ }^{12}$ In 27 families, all affected members had CD, in 43 families all had UC, and the remaining 20 had individuals affected by both CD and UC (mixed families). The majority of families ( 72 or $80 \%$ ) were composed of parents and 2-4 affected siblings, and five families had one affected sibling pair and one additional more distantly related affected member. The other 13 families contained one affected relative pair other than siblings.

\section{Genotyping}

Blood samples were collected into tubes containing sodium citrate and stored at $-30^{\circ} \mathrm{C}$ until extraction. Genomic DNA was then purified from peripheral blood leukocytes according to standard protocols ${ }^{13}$ or using a DNA isolation kit (Roche Diagnostics Co., Indianapolis, IN, USA). Eighteen different

Abbreviations: $C D$, Crohn's disease; IBD, inflammatory bowel disease; NPL, non-parametric linkage; SNP, single nucleotide polymorphism; UC, ulcerative colitis 
microsatellite markers (D16S409, D16S517, D16S411, D16S3120, D16S416, D16S419, D16S3137, D16S3032, Dl6S3112, Dl6S3140, Dl6S408, Di6S3071, D16S3094, Dl6S3132, D16S3089, Dl6S514, Dl6S503, D16S421) from the pericentromeric region of chromosome 16 were used for linkage analysis with PCR reactions and conditions as previously described. ${ }^{11}$

CARD15 SNPs R702W, G908R and L1007fsinsC were detected using the pyrosequencing approach. ${ }^{14}$ Briefly, three fragments of 106, 117 and 104 bp respectively encompassing the three SNPs were PCR amplified using $200 \mathrm{nmol} / \mathrm{l}$ of each forward and reverse primer (R702W-F: 5'-TTCCTGGCAGG GCTGTT-3' and R: 5'-biotin-CCAGACACCAGCGGGC-3'; G908R-F: 5'-TAGAGGGAGGAGGACTGTTAGTT-3 and R: 5'biotin-CCCCCTCGTCACCCACT-3'; L1007fsinsC-F: 5'-biotinTCTTCTTTTCCAGGTTGTCCA-3' and R: 5'-TCCTTACCAGA CTTCCAGGATG- $3^{\prime}$ ). The biotinylated primer in each primer pair allowed subsequent immobilisation to streptavidin coated beads. The amplification was performed in a total volume of $50 \mu \mathrm{l}$ containing $\mathrm{l} \times$ GeneAmp Buffer II, $2.5 \mathrm{mmol} / \mathrm{l}$ $\mathrm{MgCl}_{2}, 0.5 \mathrm{mmol} / \mathrm{l} \mathrm{dNTP}, 50 \mathrm{ng}$ genomic DNA and $1.5 \mathrm{U}$ AmpliTaq Gold DNA polymerase (Applied Biosystems, Foster City, CA, USA) and primers (200 nmol/l each). Conditions were $95^{\circ} \mathrm{C}$ for 10 min followed by 35 cycles at $95^{\circ} \mathrm{C}$ for $1 \mathrm{~min}, 62^{\circ} \mathrm{C}$ for $1 \mathrm{~min}, 72^{\circ} \mathrm{C}$ for $1 \mathrm{~min}$ and a final step at $72^{\circ} \mathrm{C}$ for $10 \mathrm{~min}$. PCR products $(2 \mu \mathrm{l})$ were analysed on a $3 \%(\mathrm{w} / \mathrm{v})$ agarose gel to verify size and quantity of the amplified fragment. Isolation of single stranded biotinylated templates for pyrosequencing was performed as described previously ${ }^{15}$ using solutions provided in the PSQ HS96A Sample Preparation Kit (Pyrosequencing AB, Uppsala, Sweden), streptavidin sepharose HP beads (Amersham Pharmacia Biotech, Uppsala, Sweden) and 96 well microtitre plates. Beads with bound single stranded template were suspended in $12 \mu \mathrm{l}$ of annealing buffer $\mathrm{pH} 7.6$ (20 mmol/l Tris acetate, $2 \mathrm{mmol} / \mathrm{l} \mathrm{Mg}$ acetate) and $0.5 \mu \mathrm{mol} / \mathrm{l}(6 \mathrm{pmol})$ of each pyrosequencing primer (R702W-F: 5'-CATCTGAGAAG GCCC-3'; G908R-F: 5'-CTTTTGGCCTTTTCAG -3'; L1007fsins C-F: 5'-TGTCATTCCTTTCAAGGG-3') in a PSQ HS 96 plate (Pyrosequencing $\mathrm{AB}$ ), heated at $94^{\circ} \mathrm{C}$ for $2 \mathrm{~min}$ and then cooled to room temperature to facilitate the annealing of the primer to the template. The plates were placed into the $\mathrm{PSQ}^{\mathrm{TM}} \mathrm{HS}$ 96A system following the manufacturer's recommendations. Reactions were performed at $28^{\circ} \mathrm{C}$ with annealed sequencing primer in addition to manufacturer supplied DNA polymerase, apyrase, luciferase, adenosine triphosphate sulphurylase, adenosine 5'-phosphosulphate and luciferin. Reactions consisted of stepwise elongation of the primer strand by one or more nucleotides upon sequential addition of the individual dNTPs following the dispensation order entered in the Pyrosequencing SNP Entry software (Pyrosequencing $\mathrm{AB}$ ). The sequence at each elongation step is inferred by measuring light emission as an indicator of nucleotide incorporation. The resulting sequences were analysed automatically by the SNP Evaluation software vi.l (Pyrosequencing AB). SNPs were also confirmed by DNA sequence analysis using the ABI BigDye Terminator V3.1 Cycle Sequencing Ready Reaction on a ABI 3100 DNA sequencer (Applied Biosystems) following the manufacturer's recommendations.

\section{Statistical analysis}

CARD15 SNPs genotype and allele frequencies were calculated from the 90 families' probands and 108 unrelated Italian healthy controls. Genotype and allele frequency distributions in probands and controls were compared by Fisher's exact tests. Relative risks for carriers of one or two CARD15 SNP variants compared with non-carriers were estimated as odds ratios by means of the Relrisk program [http://linkage. rockefeller.edu/ott/linkutil.htm\#relrisk].

Model free multipoint linkage analysis was performed with 18 microsatellite markers using the NPL all statistic from the Genehunter Plus program version 1.2. ${ }^{16}$ Microsatellite marker allele frequencies were calculated from allele counts in independent individuals in all our families. Map location and genetic distances of microsatellite markers were obtained from the Marshfield Center for Medical Genetics sex average map of chromosome 16 (http://research.marshfieldclinic.org/ genetics/). The genetic distance of microsatellite markers from CARD 15 was obtained from the Ensembl Human Contig Map v.12.31.1 (http://www.ensembl.org/), which gave the location of CARD15 as $25 \mathrm{~kb}$ distal to marker D16S3136. In the Marshfield sex average map of chromosome 16, D16S3136 is $0 \mathrm{cM}$ away from marker Dl6S3120, located at approximately $4 \mathrm{cM}$ from the beginning of the genetic map in our study.

Transmission disequilibrium for microsatellite marker alleles was tested by means of the Fbat computer program. ${ }^{18}$

\section{RESULTS \\ CARD15 SNP analysis}

Genotype and allele frequency distributions at the CARD15 SNPs R702W, G908R and L1007fsinsC in the IBD families' probands and in 108 unrelated unaffected controls are reported in table 1 . Probands from 20 mixed families were assigned to the respective $\mathrm{CD}$ or UC category according to their disease diagnosis (8 CD and $12 \mathrm{UC}$ ). DNA was missing from one UC proband whose family was included in the

\begin{tabular}{|c|c|c|c|c|c|c|c|}
\hline \multirow[b]{2}{*}{ SNP } & \multirow[b]{2}{*}{ Group } & \multicolumn{3}{|c|}{ Genotype counts } & \multirow[b]{2}{*}{ pt } & \multirow{2}{*}{$\begin{array}{l}\text { Rarer allele } \\
\text { frequency }\end{array}$} & \multirow[b]{2}{*}{$\mathrm{p} \ddagger$} \\
\hline & & $1 / 1$ & $1 / 2$ & $2 / 2$ & & & \\
\hline \multirow[t]{3}{*}{ R702W } & $C D$ & 21 & 9 & 0 & 0.007 & 0.15 & 0.01 \\
\hline & UC & 46 & 8 & 0 & 0.46 & 0.07 & 0.47 \\
\hline & Controls & 96 & 11 & 1 & - & 0.06 & - \\
\hline \multirow[t]{3}{*}{ G908R } & $C D$ & 27 & 6 & 0 & 0.02 & 0.09 & 0.02 \\
\hline & UC & 53 & 2 & 0 & 1 & 0.02 & 0.69 \\
\hline & Controls & 103 & 5 & 0 & - & 0.02 & - \\
\hline \multirow{3}{*}{ L1007fsinsC } & $C D$ & 29 & 4 & 2 & 0.001 & 0.11 & 0.001 \\
\hline & UC & 52 & 2 & 0 & 1 & 0.02 & 1 \\
\hline & Controls & 105 & 3 & 0 & - & 0.01 & - \\
\hline \multicolumn{8}{|c|}{$\begin{array}{l}1 / 1, \text { Homozygotes for the common variant; } 1 / 2 \text {, heterozygotes; } 2 / 2 \text {, homozygotes for the rare variant } \\
\text { tp value for difference in genotype frequencies between probands and controls by Fisher's exact test }(1 / 2 \text { and } 2 / 2 \\
\text { grouped together) } \\
\text { łp value for difference in allele frequencies between probands and controls by Fisher's exact test. }\end{array}$} \\
\hline
\end{tabular}


microsatellite linkage analysis. DNA samples from five patients failed to amplify for R702W, and DNA from one patient failed to amplify for G908R.

Genotype frequencies at the three SNPs were in HardyWeinberg equilibrium in all three groups except for L1007fsinsC in CD patients $\left(\chi^{2}=6.64,1 \mathrm{df}, \mathrm{p}=0.01\right)$, which showed excess of homozygosity for the rarer variant. Allele and genotype frequencies at all three SNPs were significantly different between $\mathrm{CD}$ probands and controls, but not between UC probands and controls (table 1).

When genotypes at all three SNPs were combined into a single CARD15 genotype (table 2), the relative risk of CD for carriers of two variants (either in the homozygous or the compound heterozygous state) compared with non-carriers was highly significant (RR 41.41, 95\% CI 4.86 to 352.95 , $\mathrm{p}=0.00001$ ) whereas the relative risk for heterozygotes at only one SNP was not (RR 1.63, 95\% CI 0.57 to 4.69 , $p=0.39$ ). A recessive mode of inheritance for susceptibility to CD linked to IBDI has been previously suggested based on a combined linkage and segregation analysis in our patient population. ${ }^{19}$

\section{Linkage analysis}

Multipoint model free linkage analysis was first performed using 18 microsatellite markers spanning approximately $28 \mathrm{cM}$ in the pericentromeric region of chromosome 16 (average distance $1.62 \mathrm{cM}$ ) on all 90 families grouped according to disease status (all IBD combined, CD, UC, and mixed). Results are shown in fig lA. The maximum multipoint NPL score occurred at the position of markers D16S408 and Dl6S3140 (74.44 cM in the Marshfield sex average genetic map) in all 90 families combined $(p=0.002)$, and in the $27 \mathrm{CD}(\mathrm{p}=0.01)$ and $43 \mathrm{UC}(\mathrm{p}=0.01)$ families. In the 20 mixed families, a non-significant peak $<1$ was observed near the q-tel end of the interval at marker Dl6S503 (83.55 cM, $\mathrm{p}=0.18$ ).

After typing the probands for R702W, G908R and Ll007fsinsC, 26 families were removed in which the proband was either heterozygote or homozygote for the rare allele at any one of the three CARD15 SNPs ( 13 CD, 6 UC and 7 mixed), and the linkage analysis was repeated (fig $1 B$ ).

The highest multipoint NPL score in all 64 families was very similar to the one observed before and still occurred near markers Dl6S408 and Dl6S3140 $(\mathrm{p}=0.002)$. A second peak of approximately the same magnitude $(p=0.003)$ was observed at the q-tel end of the genetic map close to marker D16S421 (85.94 cM). Two smaller peaks were observed near marker Dl6S419 (67.40 cM, p=0.01) and further near the centromeric end at markers D16S517 and D16S409 (58.46 cM, p = 0.03).

In the $C D$ group, there was no significant evidence of linkage to this region after the CARD15 positive families were

Table 2 Combined CARD15 SNP genotypes in 84 IBD probands typed at all three SNPs and 108 controls

\begin{tabular}{|c|c|c|c|c|c|c|}
\hline \multirow[b]{2}{*}{ Subjects } & \multicolumn{4}{|c|}{ Genotype counts } & \multirow{2}{*}{$\begin{array}{l}\operatorname{RR}_{12} \\
(95 \% \mathrm{Cl})\end{array}$} & \multirow{2}{*}{$\begin{array}{l}\mathrm{RR}_{22} \text { or } 22^{*} \\
(95 \% \mathrm{Cl})\end{array}$} \\
\hline & $1 / 1$ & $1 / 2$ & $2 / 2$ & $2 / 2 \dagger$ & & \\
\hline$C D$ & 17 & 6 & 2 & 6 & $\begin{array}{l}1.63 \\
(0.57 \text { to } 4.69)\end{array}$ & $\begin{array}{l}41.41 \\
(4.86 \text { to } 352.95)\end{array}$ \\
\hline UC & 41 & 12 & 0 & 0 & $\begin{array}{l}1.36 \\
(0.60 \text { to } 3.05)\end{array}$ & - \\
\hline Controls & 88 & 19 & 1 & 0 & - & - \\
\hline
\end{tabular}

$1 / 1$, homozygotes for the common variant at all three SNPs; $1 / 2$, single heterozygotes; $2 / 2$, homozygotes at one of the three SNPs; $2 / 2+$, heterozygotes at two SNPs.
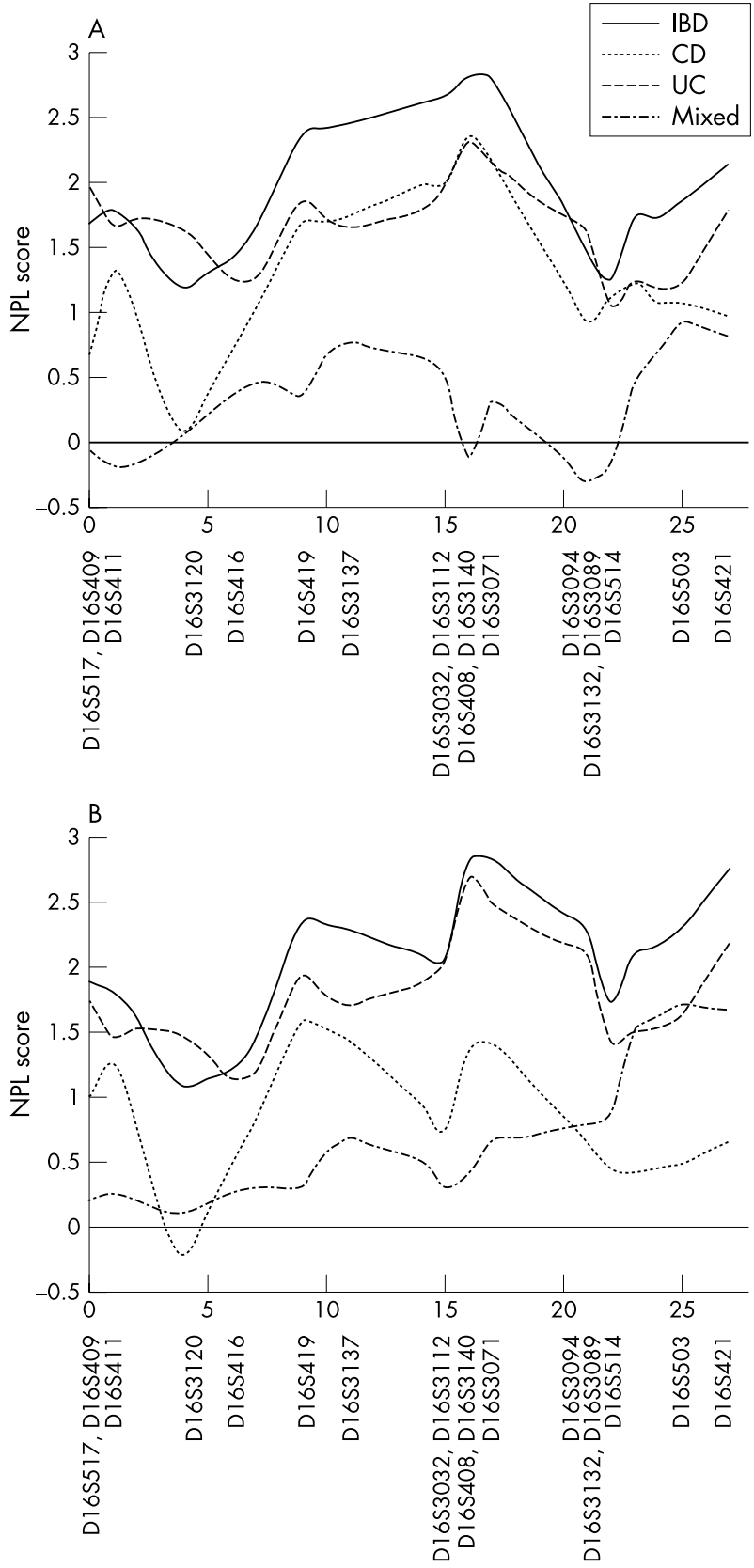

CM

Figure 1 Multipoint NPL scores for chromosome 16 microsatellite markers. (A) All families irrespective of CARD15 SNPs status; (B) only families with probands negative for CARD 15 SNPs analysis.

removed (all p values $>0.05$ ). Interestingly, the NPL at the location of marker Dl6S3120, which is the nearest marker to CARD15 included in our analysis, was now negative. The maximum NPL was observed at marker D16S419 (67.40 cM, $\mathrm{p}=0.06$ ), which is about $5 \mathrm{cM}$ away from CARD15.

In contrast, linkage to D16S408 was even more significant in the 37 CARD15 negative UC families $(\mathrm{p}=0.003)$. Additional smaller peaks were observed near the ends of the genetic map, and the overall profile was very similar to that described for the whole IBD sample. In the mixed families, linkage to D16S503 near the q-tel end of our interval was more pronounced $(\mathrm{p}=0.04)$ when families with CARD15 SNP positive probands were removed. 


\section{Linkage disequilibrium analysis}

Family based tests of association in the three groups of 14 $\mathrm{CD}, 37 \mathrm{UC}$, and 13 mixed families that were negative at the CARD15 SNP analysis did not show any significant association of any of the alleles of 18 microsatellite markers to disease status (all p values $>0.05$ ). However, given their small size, it is possible that inability to detect associations in our samples was due to lack of power.

\section{DISCUSSION}

After its initial report by Hugot et al in 1996, linkage of CD to the IBDI locus in the pericentromeric region of chromosome 16 was consistently replicated in several independent groups of patients, although with some variation in the location of the linkage peak across different studies. ${ }^{6}$ This was an unusual finding in the search for susceptibility genes in complex traits by genetic linkage analysis, which is often characterised by lack of replication of initial positive results in subsequent studies. The search for the IBDI gene culminated in the discovery that allelic variants of SNPs in the CARD15 gene conferred an increased risk of developing $\mathrm{CD},{ }^{8-10}$ particularly when present on both homologous copies of chromosome 16 in either the homozygous or the compound heterozygous state. Once again, this finding was consistently replicated in several populations, ${ }^{4}$ including some in which linkage to the $I B D I$ region was less than significant. ${ }^{20}$

Linkage of UC, the other common form of IBD, to the IBDI locus was reported usually to be negative or non-significant ${ }^{6}$ with few exceptions. ${ }^{7}$ We first reported a positive linkage of markers in the $I B D I$ region to both CD and UC in our Italian patient population. ${ }^{11}$ While we were extending the analysis of the $I B D 1$ region to a larger sample of families and a more dense map of markers, the identification of the association of CD with CARD15 SNP alleles ${ }^{8-10}$ prompted us to type our families for the same SNPs, and re-evaluate our linkage findings after exclusion of those families in which the probands were carriers of CARD15 SNP alleles known to confer susceptibility to CD.

Similarly to results in other populations, all three CARD15 SNPs characterised in this study (R702W, G908R, and L1007fsinsC) showed significantly higher frequencies of the rarer alleles in the CD, but not in the UC probands. Multipoint model free linkage analysis with markers from the $I B D I$ region became even more significant in our UC families (with a peak close to marker Dl6S408, which is about $12 \mathrm{cM}$ away from the location of CARD15) after removal of six UC families whose probands were heterozygous carriers of one of the three CARD15 SNPs. In contrast, the significance of linkage to this region was markedly reduced in our CD group after removal of the families with CARD 15 positive probands, suggesting that the three known SNPs did account for most of the IBDI linked susceptibility to $\mathrm{CD}$ in our families. A much smaller peak was observed in the mixed families group near the q-tel end of the interval included in our analysis (approximately $20 \mathrm{cM}$ away from CARD15). In this case also, significance increased after removal of seven families in which the probands were carriers of one of the three CARD15 SNPs. These observations point to the existence of a UC susceptibility gene in the IBDI region in our families.

The presence of additional IBD loci in the pericentromeric region of chromosome 16 independent of CARD15 has been suggested by Hampe et $\mathrm{al}^{21}$ on the basis of the observation of positive linkage in their CARD15 negative IBD families. In their study, linkage was more significant in the CD families than in all IBD families combined, and was marginal in their group of UC families. While linkage was positive across a large pericentromeric region, the observation of positive association with alleles of a microsatellite marker, D16S3068, located near the centromere on 16p, led these authors to detect significant association to random SNPs in this area. The nearest markers to D16S3068 included in our study are D16S409 and D16S517, located on chromosome 16q approximately $10 \mathrm{cM}$ away from Dl6S3068 according to the Marshfield chromosome 16 genetic map. Although we observed a small peak near these markers in the IBD and UC groups, our data point to a more distal $16 q$ location for the susceptibility locus in our families. Interestingly, based on the observation of multiple positive linkage peaks in the intervals flanking CARD15, Hampe et $a^{21}$ also suggested that more than one additional IBD gene may be located in this region.

We cannot exclude that rarer CARD15 SNPs other than those typed in this study are present in our patients and account for some of the positive linkage to this region in our families. In this respect, it is of interest that even in the CD families the maximum NPL score occurred at marker D16S408, which is about $12 \mathrm{cM}$ away from CARD15, and that the minimum score occurred at Dl6S3120, which is the nearest marker to CARD15 included in our analysis. Nonetheless, 13 CD families out of 27 were found to be positive for the CARD15 SNPs (with five heterozygous and eight homozygous or compound heterozygous probands). This observation points to the difficulty of correctly mapping susceptibility genes for complex traits by linkage analysis. ${ }^{20}$ The relatively small sample size and the presence of both linked and unlinked families may result in a localisation of the linkage peak away from the actual susceptibility gene location. The positive linkage we observed in the $I B D 1$ region might indicate the presence of different CARD15 SNPs from those we tested conferring susceptibility to IBD in our population. However, the involvement of rarer CARD15 SNPs in UC has been excluded in patients from several European populations, including some from Italy. ${ }^{22}$ It seems unlikely that CARD15 plays a different role in our UC patients from that observed in other populations.

In conclusion, these results point to the presence of a UC susceptibility locus in the chromosome 16 pericentromeric region in our families. Whether this is at least in part due to the presence of rarer CARD15 SNPs or to a completely independent gene, remains to be determined.

\section{ACKNOWLEDGEMENTS}

We thank the patients and their families who provided blood samples for this study.

Cooperative investigators of the IG-IBD (Italian Group for Inflammatory Bowel Disease): G Iaquinto, M Campieri, P Gionchetti (Clinica Medica, Policlinico S Orsola, Bologna), D Valpiani, E Ricci (Divisione di Medicina, Forli'), G Frieri, M T Pimpo (Cattedra di Gastroenterologia, Universita L'Aquila), S Giaccari, L Grasso (Divisione di Gastroenterologia, Galatina), M Saibeni, R de Franchis (Gastroenterologia, Ospedale Maggiore IRCCS, Milano), G Bianchi Porro (Gastroenterologia, Ospedale Sacco, Milano), G Riegler, F Morace (Cattedra di Gastroenterologia, II ${ }^{\mathrm{a}}$ Universita di Napoli), S Cucchiara, O Borrelli (Dipartimento di Pediatria, II ${ }^{\text {a }}$ Universita di Napoli), F Castiglione, G Mazzacca (Cattedra di Gastroenterologia, II Universita Napoli), C Prantera, A Andreoli (Divisione di Gastroenterologia, Ospedale N Regina Margherita, Roma), C Papi, L Capurso (Gastroenterologia, S Filippo Neri, Roma), R D'inca, G Sturniolo (Cattedra di Gastroenterologia, Universita di Padova), M Oliva (Gastroenterologia, Ospedale Cervello, Palermo), G Lombardi, S Fiorella, G Corritore, T Latiano (Gastroenterologia, Ospedale CSS-IRCSS, San Giovanni Rotondo), M Rizzetto, M Astegiano, F Bresso (Dipartimento di Gastroenterologia, Ospedale Molinette, Torino), A Pera (Divisione di Gastroenterologia, Ospedale Mauriziano, Torino).

This work was supported in part by grants from the Center for Translational Medicine at Thomas Jefferson University (PF) and from the Italian Ministry of Health (RC0203GA15, VA). 
Authors' affiliations

V Annese, A Latiano, O Palmieri, A Andriulli, Divisione di

Gastroenterologia, IRCCS Casa Sollievo della Sofferenza, San Giovanni Rotondo (FG), Italy

O Palmieri, P Fortina, Center for Translational Medicine, Department of Medicine, Thomas Jefferson University, Philadelphia, PA, USA

H-H Li, M Devoto, Department of Biomedical Research, Nemours Children's Clinic, Wilmington, DE, USA

P Forabosco, Istituto di Genetica delle Popolazioni, CNR, Alghero (SS), Italy

A Ferraris, B Dallapiccola, IRCCS CSS San Giovanni Rotondo and CSSMendel, Roma and Dipartimento di Medicina Sperimentale e Patologia, Universita' La Sapienza, Roma, Italy

M Vecchi, IRCCS Ospedale Maggiore, Milano, Italy

S Ardizzone, Ospedale Sacco, Milano, Italy

M Cottone, Ospedale Cervello, Palermo, Italy

E Rappaport, Joseph Stokes Jr Research Institute, The Children's Hospital of Philadelphia, Philadelphia, PA, USA

M Devoto, Dipartimento di Oncologia, Biologia e Genetica, Universita' di Genova, Italy

Correspondence to: Dr M Devoto, Genetic Epidemiology Research Laboratory, Nemours Children's Clinic, PO Box 269, Wilmington, DE 19899, USA; mdevoto@nemours.org

\section{REFERENCES}

1 Sandler RS. Epidemiology of inflammatory bowel disease. In: Targan SR, Shanahan F, eds. Inflammatory bowel disease. From bench to bedside. Williams \& Wilkins: Baltimore, 1994:5-31.

2 Satsangi J, Jewell DP, Bell Jl. The genetics of inflammatory bowel disease. Gut 1997:40:572-4.

3 McConnell RB. Genetics of inflammatory bowel disease. In: Allan RN, Keighley MRB, Alexander-Williams J, Hawkins C, eds. Inflammatory bowel disease. London: Churchill-Livingston, 1990:11-23.

4 Bonen DK, Cho JH. The genetics of inflammatory bowel disease. Gastroenterology 2003;124:521-36.

5 Hugot JP, Laurent-Puig P, Gower-Rousseau C, Olson JM, Lee JC, Beaugerie L, Naom I, Dupas JL, Van Gossum A, Orholm M, Bonaiti-Pellie C, Weissenbach J, Mathew CG, Lennard-Jones JE, Cortot A, Colombel JF, Thomas G. Mapping of a susceptibility locus for Crohn's disease on chromosome 16. Nature 1996:379:821-3.

6 Cavanaugh J, The IBD International Genetics Consortium. International collaboration provides convincing linkage replication in complex disease through analysis of a large pooled data set: Crohn disease and chromosome 16. Am J Hum Genet 2001;68:1165-71.

7 Mirza MM, Lee J, Teare D, Hugot JP, Laurent-Puig P, Colombel JF, Hodgson SV, Thomas G, Easton DF, Lennard-Jones JE, Mathew CG. Evidence of linkage of the inflammatory bowel disease susceptibility locus on chromosome 16 (IBD1) to ulcerative colitis. J Med Genet 1998;35:218-21.

8 Hugot JP, Chamaillard M, Zouali H, Lesage S, Cezard JP, Belaiche J, Almer S, Tysk C, O'Morain CA, Gassull M, Binder V, Finkel Y, Cortot A, Modigliani R, Laurent-Puig P, Gower-Rousseau C, Macry J, Colombel JF, Sahbatou M,
Thomas $G$. Association of NOD2 leucine-rich repeat variants with susceptibility to Crohn's disease. Nature 2001;41 1:599-603.

9 Ogura Y, Bonen DK, Inohara N, Nicolae DL, Chen FF, Ramos R, Britton H, Moran T, Karaliuskas R, Duerr RH, Achkar JP, Brant SR, Bayless TM, Kirschner BS, Hanauer SB, Nunez G, Cho JH. A frameshift mutation in NOD2 associated with susceptibility to Crohn's disease. Nature 2001;41 1:603-6.

10 Hampe J, Cuthbert A, Croucher PJ, Mirza MM, Mascheretti S, Fisher S, Frenzel H, King K, Hasselmeyer A, MacPherson AJ, Bridger S, van Deventer S, Forbes A, Nikolaus S, Lennard-Jones JE, Foelsch UR, Krawczak M, Lewis C, Schreiber S, Mathew CG. Association between insertion mutation in NOD2 gene and Crohn's disease in German and British populations. Lancet 2001;357:1925-8.

11 Annese V, Latiano A, Bovio P, Forabosco P, Piepoli A, Lombardi G Andreoli A, Astegiano M, Gionchetti P, Riegler G, Sturniolo GC, Clementi M, Rappaport E, Fortina P, Devoto M, Gasparini P, Andriulli A. Genetic analysis in Italian families with inflammatory bowel disease supports linkage to the IBDI locus. A GISC study. Eur J Hum Genet 1999;7:567-73.

12 Lennard-Jones JE. Classification of inflammatory bowel disease. Scand J Gastroenterology 1989;24(suppl. 170):2-6.

13 Sambrook J, Fritsch EF, Maniatis F. Molecular cloning: a laboratory manual. Cold Spring Harbor, New York: Cold Spring Harbor Laboratory Press, 1989.

14 Fakhrai-Rad H, Pourmand N, Ronaghi M. Pyrosequencing: an accurate detection platform for single nucleotide polymorphisms. Hum Mutat 2002; 19:479-85.

15 Ferraris A, Rappaport E, Santacroce R, Pollak E, Krantz I, Toth S, Margaglione M, Restagno G, Dallapiccola B, Surrey S, Fortina P. Pyrosequencing analysis for detection of mutations associated with hereditary hearing loss in the connexin 26 gene and mitochondrial DNA. Hum Mutat 2002;20:312-20.

16 Kruglyak L, Daly MJ, Reeve-Daly MP, Lander ES. Parametric and nonparametric linkage analysis: a unified multipoint approach. Am J Hum Genet 1996;58:1347-63

17 Kong A, Cox NJ. Allele-sharing models: LOD scores and accurate linkage tests. Am J Hum Genet 1997:61:1179-88.

18 Horvath S, Xu X, Laird NM. The family based association test method: strategies for studying general genotype-phenotype associations. Eur J Hum Genet $2001 ; 9: 301-6$

19 Forabosco P, Collins A, Latiano A, Annese V, Clementi M, Andriulli A, Fortina $P$, Devoto $M$, Morton NE. Combined segregation and linkage analysis of inflammatory bowel disease in the IBDI region using severity to characterise Crohn's disease and ulcerative colitis. Eur J Hum Gene 2000;8:846-52.

20 van Heel DA, McGovern DP, Cardon LR, Dechairo BM, Lench NJ, Carey AH, Jewell DP. Fine mapping of the IBDI locus did not identify Crohn diseaseassociated NOD2 variants: implications for complex disease genetics. Am J Med Genet 2002;111:253-9.

21 Hampe J, Frenzel H, Mirza MM, Croucher PJ, Cuthbert A, Mascheretti S Huse K, Platzer M, Bridger S, Meyer B, Nurnberg P, Stokkers P, Krawczak M, Mathew CG, Curran M, Schreiber S. Evidence for a NOD2-independent susceptibility locus for inflammatory bowel disease on chromosome 16p. Proc Natl Acad Sci USA 2002;99:321-6.

22 Lesage S, Zouali H, Cezard JP, Colombel JF, Belaiche J, Almer S, Tysk C, O'Morain C, Gassull M, Binder V, Finkel Y, Modigliani R, Gower-Rousseau C, Macry J, Merlin F, Chamaillard M, Jannot AS, Thomas G, Hugot JP, EPWG IBD Group, EPIMAD Group, GETAID Group. CARD15/NOD2 mutational analysis and genotype-phenotype correlation in 612 patients with inflammatory bowel disease. Am J Hum Genet 2002;70:845-57. 